\title{
Prenatal Ethanol-induced Effect on Cell Count of Pars Distalis of Pituitary Gland in the Rat Pups
}

\author{
Nadia Rashid 1 and M. Yunus Khan 2
}

\begin{abstract}
Objective: To determine the effects of prenatal administration of ethanol on cell count in pars distalis of pituitary gland in the rat pups.

Study Design: Experimental study.

Place and Duration of Study: Department of Anatomy, College of Physicians and Surgeons Pakistan, Regional Centre, Islamabad, Pakistan, from April 2014 to April 2015.

Methodology: Sixteen female rats (Sprague Dawley) were selected by random sampling method. Rats were mated and divided into control group A and experimental group B. From gestational day 10 to 18, mother rats received intraperitoneal injection of ethanol (Group B) and normal saline (Group A). Mother rats were allowed to complete their gestation and deliver spontaneously. When pups were born, only male pups were selected for the study. They were reared till day five. At $5^{\text {th }}$ day, pituitary glands were taken out and histological study was done in PAS-OG stain. Cell count was made in unit area $\left(10,000 \mu^{2}\right)$ of pars distalis of pituitary gland. Student t-test was applied for analysing the data of cell counts in unit area. Results: Mean acidophil count was reduced in experimental group (70.19 \pm 11.4$)$ as compared to control group (92.65 $\pm 8.52, p<0.001)$. Mean basophil count was reduced in experimental group $(27.05 \pm 3.9)$ in comparison to control group (34.03 $\pm 7.9, p<0.001)$. Mean chromophobe count was increased $(131.95 \pm 10.7)$ in experimental group against the control group $(104.62 \pm 7.62, p<0.001)$.

Conclusion: Pups exposed to ethanol during gestation, showed significant reduction in acidophil and basophil count while increase in chromophobe cell count in pars distalis of pituitary gland.
\end{abstract}

Key Words: Ethanol, Cell count, Anterior pituitary gland, Growth, Rats.

\section{INTRODUCTION}

Alcohol (ethyl alcohol or ethanol) is most extensively used psychotropic and anxiolytic drug in industrialised world. ${ }^{1}$ It is the most annihilating agent which is responsible for $4 \%$ worldwide deaths. ${ }^{2}$

Prenatal development comprises series of genetic and epigenetic events that transform unspecified central nervous system to a well-developed complex system that processes information and plans action. ${ }^{3}$ Maternal exposure to exogenous agents disrupts such complex developmental processes resulting in anomalies. ${ }^{3}$ In 1968, Lemoine and colleagues identified a syndrome of birth defects with small head size, indistinct philtrum, narrow upper lip, low nose bridge and small brain size in infants of alcoholic mothers. ${ }^{4}$ Children suffering from fetal alcohol syndrome (FAS) are mentally and developmentally retarded. 4 In pregnancy, amniotic fluid acts as a reservoir for ethanol storage. ${ }^{5}$

1 Department of Anatomy, Foundation University Medical College (FUMC), Islamabad, Pakistan

2 Department of Anatomy, CPSP, Regional Center, Islamabad, Pakistan

Correspondence: Dr. Nadia Rashid, Department of Anatomy, Foundation University Medical College (FUMC), Islamabad, Pakistan

E-mail:dr.nadiarashid@hotmail.com

Received: June 14, 2018; Revised: January 02, 2019;

Accepted: January 02, 2019
Prevalent evidence suggests that neurodevelopmental pathogenesis of ethanol is due to inhibition of L1 adhesion molecule, production of free radicals 6 and by inhibiting expression of Pax6 gene. ${ }^{7}$ Peng et al. observed reduced expression (90\%) of Pax6 gene in Xenopus embryo exposed to only $0.3 \%$ ethanol concentration, resulting in microcephaly and growth retardation in it. ${ }^{7}$ Moreover, Pax6 gene encoded protein is responsible for expression of $\mathrm{L} 1$ cell adhesion gene. 8 So, ethanol exerts its teratogenic effects through direct inhibition of $L 1$ adhesion molecule or through inhibition of Pax6 gene encoded expression of $L 1$ cell adhesion gene. Similarly, in experiments involving overexpression of Pax6 transcription factor to alcohol exposed fetal radial glial cell cultures resulted in proliferation of neurons. ${ }^{9}$

Pax6 expression is required for normal ocular, 10 neural, ${ }^{11}$ and pancreatic development, 12 as well as development of dorsoventral axis of pituitary gland.13

Anterior pituitary gland develops from Rathke's pouch. Multiple intrinsic and extrinsic signalling molecules like BMP2 and fgf8 affect pituitary organogenesis including the pattern of appearance of different anterior pituitary cell types. ${ }^{14}$ Pax6 transcripts show dorsal high to ventral low expression pattern in Rathke's pouch. Normal Pax6 expression is required for controlling the established boundaries of somatotrophs, lactotrophs and thyrotrophs. ${ }^{15}$ In the absence of Pax6, there is dorsal expansion of transcriptional determinants of ventral cell types such as 
thyrotrophs and gonadotrophs which increase in number and; dorsal cell types such as somatotrophs and lactotrophs decrease in number. 15

It is known that ethanol exposure during intrauterine life leads to growth retardation but whether this effect is quantitative in terms of cell count of pars distalis was not investigated previously.

The objective of this study was to determine the effects of prenatal administration of ethanol on cell count in pars distalis of pituitary gland in the rat pups.

\section{METHODOLOGY}

This experimental study was carried out at Department of Anatomy, College of Physicians and Surgeons Pakistan, Regional Centre, Islamabad, Pakistan, from April 2014 to April 2015. For breeding, 16 female and four male Sprague Dawley rats of ages 70 to 120 days were obtained by random sampling method from National Institute of Health $(\mathrm{NIH})$, Islamabad. Rats with some physical deformity or disease were excluded from the research. Nulliparous female rats were numbered and weighed. Male rats were introduced into the cages for mating. Vaginal smears were collected every morning between 07:00 and 09: 00 AM. Pregnancy was diagnosed by presence of spermatozoa in vaginal smears (Figure 1).

Pregnant female rats were divided equally into control group (A) and experimental group (B), and shifted to numbered cages keeping one female rat in one cage. Group B was injected intraperitoneally with $20 \%$ ethanol solution in normal saline at a dose of $4.44 \mathrm{ml} / \mathrm{kg} / \mathrm{day},{ }_{15}$ while group $A$ was injected intraperitoneally with equal volume of normal saline from $\mathrm{G} 10$ to $\mathrm{G} 18$. Both groups were exposed to the same environment, i.e., 12-hour light-dark cycle, controlled humidity, temperature, and free access to standard laboratory rat food and drinking water. Twenty percent solution of ethanol was prepared using $100 \%$ ethanol and normal saline. A $10-\mathrm{ml}$ syringe with $24 \mathrm{G}$ needle was used for intraperitoneal injection. When pups were 5 days old, male pups were selected for the experiment. They were observed for their activities and any gross deformities. Their body weights were recorded using precise digital scale and lengths were measured by measuring length of thread extended from vertex to the start point of tail.

Rat pups were euthanised by chloroform inhalation. Skulls were immediately removed and pituitaries were taken out to minimise postmortem changes. Skin of the skull was removed and frontal and parietal bones were cut at their posterior, lateral and anterior margins. The thin bone flap was reflected laterally and brain was exposed.

Brain was lifted at its anterior end and reflected posteriorly by cutting optic nerves and pituitary stalk. This exposed the pituitary gland lying in Sella turcica. Stereomicroscope was used for fine dissection. As the size of pituitary gland was very small for handling, so it was removed along with Sella turcica of sphenoid bone.

The specimens were then numbered according to groups and fixed in Helly's formol for 12 to 20 hours at $4^{\circ} \mathrm{C} .16$ Specimens were processed for paraffin embedding. Rat pituitary gland has disc shape with two wings of pars distalis. ${ }^{17}$ Coronal sections were cut at 6 micrometer thickness and stained with periodic acid schiff-orange $G$ (PAS-OG) method. ${ }^{18}$ With this method, basophils appear magenta coloured, acidophils and red blood cells yellow, and chromophobes pale (Figures 2 and 3 ). Cell count in pars distalis of pituitary gland was made at high power objective (100X). Before observing the slides, ocular of the microscope was fitted with graticule with 400 small squares to facilitate counting of cells. By using a certified graduated stage micrometer, area of the graticule was calculated to be $10,000 \mu^{2}$. Ten equally spaced sections were selected for each animal. In each section, cell count was made using graticule in both halves of the adeno-hypophyis. Nuclei of acidophils, basophils and chromo-phobes lying within the graticule were counted and recorded. Mean cell count of the sections was made. The data was analysed statistically with the statistical package for social sciences (SPSS) computer

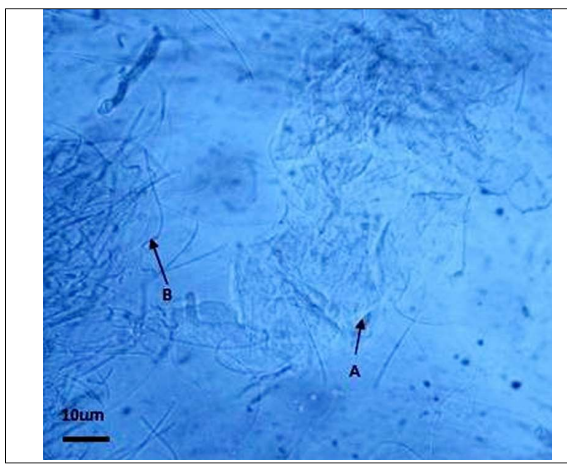

Figure 1: High magnification photomicrograph of rat's vaginal smear stained with methylene blue showing vaginal cornified cells (A) and rat sperms (B). Scale bar $=10 \mu \mathrm{m}$, Magnification $=1000$. When sperms were seen in vaginal smear, this day was labelled as gestational day zero for mother rat. Female rats were labelled as gestational day zero $(\mathrm{G} 0)$.

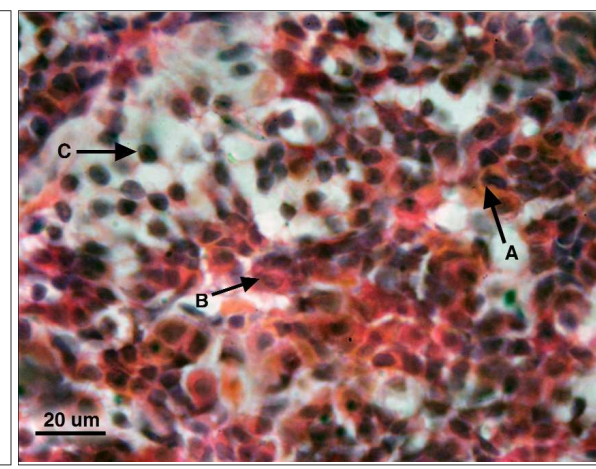

Figure 2: Coronal section of pituitary gland of rat pup of control group A showing acidophils (A) and basophils (B) with chromophobes (C) PAS-OG staining.

Scale bar $=20 \mu \mathrm{m}$, Magnification $=1000$

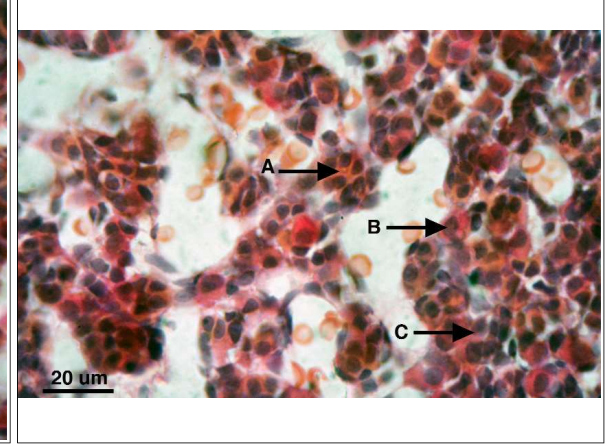

Figure 3: Coronal section of pituitary gland of rat pup of experimental group $B$ showing sparse number of acidophils $(A)$ and basophils $(B)$ with chromophobes (C). PAS-OG staining. Scale bar $=20 \mu \mathrm{m}$, Magnification $=1000$. 
Table I: Comparison of mean cell count (Per unit area) in Pars distalis of pituitary gland of control group $A$ with ethanol exposed group B.

\begin{tabular}{l|c|c|l}
\hline Parameter & $\begin{array}{c}\text { Control A } \\
\text { pups }\end{array}$ & $\begin{array}{c}\text { Experimental B } \\
\text { pups }\end{array}$ & $p$-value \\
& $n=26$ & $n=23$ & \\
& Mean \pm SD & Mean $\pm S D$ & \\
\hline Number of acidophils per unit area & $92.65 \pm 8.62$ & $70.19 \pm 11.4$ & $p<0.001^{*}$ \\
Number of basophils per unit area & $34.03 \pm 7.9$ & $27.05 \pm 3.9$ & $p<0.001^{*}$ \\
Number of chromophobe per unit area & $104.62 \pm 7.62$ & $131.95 \pm 10.7$ & $p<0.001^{*}$ \\
\hline$n=$ Number of specimens; $\quad S D=$ Standard deviation; * $\quad$ Significant
\end{tabular}

software programme, version 21. Student t-test was used for analysing any significant differences between the means of number of acidophils, basophils and chromophobes in the rat pups of experimental and control groups. Mean \pm SD was used for continuous variables. Level of significance $<0.05$ was taken as significant (Table I).

\section{RESULTS}

The mean acidophils cell count per unit area $\left(10,000 \mu^{2}\right)$ of pars distalis of pituitary gland of experimental group $B$ was reduced from $92.65 \pm 8.52$ in control group $A$ to $70.19 \pm 11.4$ in experimental group $B(p<0.001)$. Similarly basophil count per unit area $\left(10,000 \mu^{2}\right)$ was also reduced from $34.03 \pm 7.9$ in control group $A$ to 27.05 \pm 3.9 in experimental group B $(p<0.001)$. The mean chromophobes cell count per unit area $\left(10,000 \mu^{2}\right)$ of pars distalis of pituitary gland of experimental group $B$ was $131.95 \pm 10.7$; whereas, mean cell count of control group A was $104.62 \pm 7.62$ ( $p<0.001)$. This difference in cell counts of control and experimental groups were statistically significant (Table I).

\section{DISCUSSION}

Ingestion of ethanol during pregnancy results in abnormal fetal development in both human subjects and experimental animals. In humans, prenatal ethanol exposure causes a syndrome known as fetal alcohol syndrome.

In the present work, with the experimental protocol, high blood alcohol concentration was used via daily ethanol injections from gestational day 10 to gestational day 18 , to mimic human FAS in a rat model. ${ }^{15}$ This study has shown teratogenic effects of ethanol on the development of pars distalis of pituitary gland by affecting cell count.

Number of acidophils was most affected by the prenatal ethanol exposure during this experiment. This effect could be explained on the molecular basis of development of pars distalis of pituitary gland. Development of pituitary gland along with other organs like ocular, 10 neural, ${ }^{11}$ and pancreatic tissue, ${ }^{12}$ requires normal expression of Pax6 gene. Pax6 is expressed in murine and zebrafish embryonic pituitary. ${ }^{7}$ Homozygous Pax6 mutation leads to death of mice before birth. Pax6 mutated mice had low serum growth hormone $(\mathrm{GH})$ and prolactin ( $P R L$ ) level during embryonic as well as postnatal life, although mRNA for these peptide hormones was present. So Pax6 affected levels of $\mathrm{GH}$ and PRL by affecting translational and secretory mechanism. ${ }^{7}$

It is documented that microcephaly and growth retardation caused by ethanol ingestion depends on the dose in which it is taken during prenatal development. This effect of ethanol is produced by reducing the expression of various neural genes, of which Pax6 is the most susceptible. Just $0.3 \%$ alcohol concentration could reduce $90 \%$ of Pax6 expression. ${ }^{7}$ Ethanol, which was given in this experiment prenatally, could have exerted its teratogenic effects through inhibiting $\mathrm{L} 1$ adhesion molecule either directly or through inhibiting Pax6. Reduction of Pax6 in turn would have resulted in reduction in number of acidophils in pars distalis of pituitary gland.

The basophil count in pars distalis of pituitary gland was also reduced in this experiment. This reduction in basophil count could be explained on the previous research that showed that Pax6 was required for the development of gonadotropin releasing hormone neurons. In mice with Pax6 mutation, luteinizing hormone $\beta$ (LH $\beta$ ) expressing cells are not detected in pituitary gland. ${ }^{14}$ So, these could be the cells which were inhibited by ethanol through its inhibitory effects on Pax6.

As far as number of chromophobes was concerned, their number increased in experimental group as compared to control. Their number was significantly increased from $104.62 \pm 7.62(p<0.001)$ in control group to $131.95 \pm 10.7$ in experimental group pups $(p<0.001)$. Chromo-phobes represent a heterogeneous group including stem cells and undifferentiated progenitor cells as well as any degranulated cells present. ${ }^{19}$ The number of chromophobes could be explained on the basis of comparative decrease in number of acidophils and basophils in experimental pups.

Limitation of the study was that expression of Pax6 could not be checked simultaneously on the ethanol exposed experimental group.

\section{CONCLUSION}

Prenatal ethanol exposure showed inhibitory effects on the development of pars distalis of pituitary gland as shown by decrease in the cell count of acidophils and basophils and increase in cell count of chromophobes.

\section{REFERENCES}

1. Miranda-Morales RS, Nizhnikov ME, Waters DH, Spear NE. New evidence of ethanol's anxiolytic properties in infant rat. Alcohol 2014; 48:367-74.

2. Ornoy A, Ergaz Z. Alcohol abuse in pregnant woman: Effect on fetus and newborn, mode of action and maternal treatment. Int J Environ Res Public Health 2010; 7:364-79. 
3. Perera F, Herbstman J. Prenatal environmental exposures, epigenetic and disease. Reprod Toxicol 2011; 31:363-73.

4. Lemoine $P$, Harousseau H, Borteryu JP, Menuet JC. Les infants des parents alcoholiques: Abnormalities observees a propos de 127 cas. Ouest Medical 1968; 21:476-82.

5. Ng PK, Cottle MK, Baker JM, Jhonson B, van Muyden P, van Petten GR. Ethanol kinetics during pregnancy, study in ewes and their fetuses. Prog Neuropsychopharmacol Biol Psychiatry 1982; 6:37-42.

6. Tang N, He M, O'Riordan MA, Farkas C, Buck K, Lemmon V, et al. Ethanol inhibits L1 cell adhesion molecule activation of mitogen-activated protein kinase. J Neurochem 2006; 96:1480-90.

7. Peng $\mathrm{Y}$, Yang $\mathrm{PH}, \mathrm{Ng} \mathrm{SS}$, Wong OG, Liu J, He ML, et al. A critical role of Pax6 in alcohol-induced fetal microcephaly. Neurobiol Dis 2004; 16:370-6.

8. Meech R, Kallunki P, Gerald M, Jones FS. A binding site for homeodomain and Pax protein is necessary for $\mathrm{L} 1$ cell adhesion molecule gene expression by Pax 6 and bone morphogenetic proteins. PNAS 1999; 96:2420-5.

9. MO Z, Milivojevic V, Zecevic N. Enforced Pax6 expression rescues alcohol induced defects of neuronal differentiation in cultures of human cortical progenitor cell. Alcohol Clin Exp Res 2012; 36:1374-84.

10. Grindley JC, Davidson DR, Hill RE. The role of Pax-6 in eye and nasal development. Development 1995; 121:1433-42.

11. Tyas DA, Pearson H, Rashbass $P$, Price DJ. Pax6 regulates cell adhesion during cortical development. Cereb Cortex 2003; 13:612-9.

12. St-Onge L, Sosa-Pineda B, Chowdhury K, Mansouri A, Gruss P. Pax6 is required for differentiation of glucagon producing alpha cells in mouse pancreas. Nature 1997; 387:406-9.

13. Kioussi C, O'Connell S, St Onge L, Treier M, Gleiberman AS, Gruss $\mathrm{P}$, et al. Pax6 is essential for establishing ventral-dorsal cell boundaries in pituitary gland development. Proc Natl Acad Sci USA 1999; 96:14378-82.

14. Buntley CA, Zidehsarai MP, Grindley JC, Parlow AF, Barth-Hall S, Roberts VJ, et al. Pax6 is implicated in murine pituitary endocrine function. Endocrine 1999; 10:171-7.

15. Arrone MP, Evard SG, Mirochnic S, Brusco A. Prenatal ethanol exposure reduces expression of transcriptional factor Pax6 in developing rat brain. Ann NY Acad Sci 2008; 1139:478-97.

16. Weinburg K, Fitschen W. The pituitary remnant after partial hypophysectomy in the rat. BrJ Exp Pathol 1959; 40:232-42.

17. Brandi-Baicco A, Balme E, Brinder M, Chandra S, Hellmann J, Honerhoff MJ et al. Non-proliferative and proliferative lesions of rat and mouse endocrine system. J Toxicol Pathol 2018; 31: 1s-95s.

18. Bancroft HD, Gamble M. (Eds.). Theory and practice of histological techniques. ed $5^{\text {th }}$. London: Churchill Livingstone; 2002. p. 361

19. Mescher AL. Junquira's basic histology text and atlas. ed $13^{\text {th }}$. United states: The McGrew-Hill company; 2013. p.409. 